\title{
Preparation of a chicken scFv to analyze gentamicin residue in animal derived food products
}

Cui Li, Jinxin He, Hao Ren, Xiaoying Zhang*, Enqi Du, Xinping Li

College of Veterinary Medicine, Northwest A\&F University, Yangling, 712100,

Shaanxi, China;

\section{Supporting Information Abstract}

The complete supplementary information (SI) section has the following information:

Figure S-1, the amino acid sequences of the scFvs. A complete table of content is shown below.

\section{Table of Content}

1. Cover Page page S-1

2. Figure $\mathrm{S}-1$ page S-2

3. The amino acid sequences of the scFvs page S-3 
Figure S-1 The results of PCR of ten phage clones

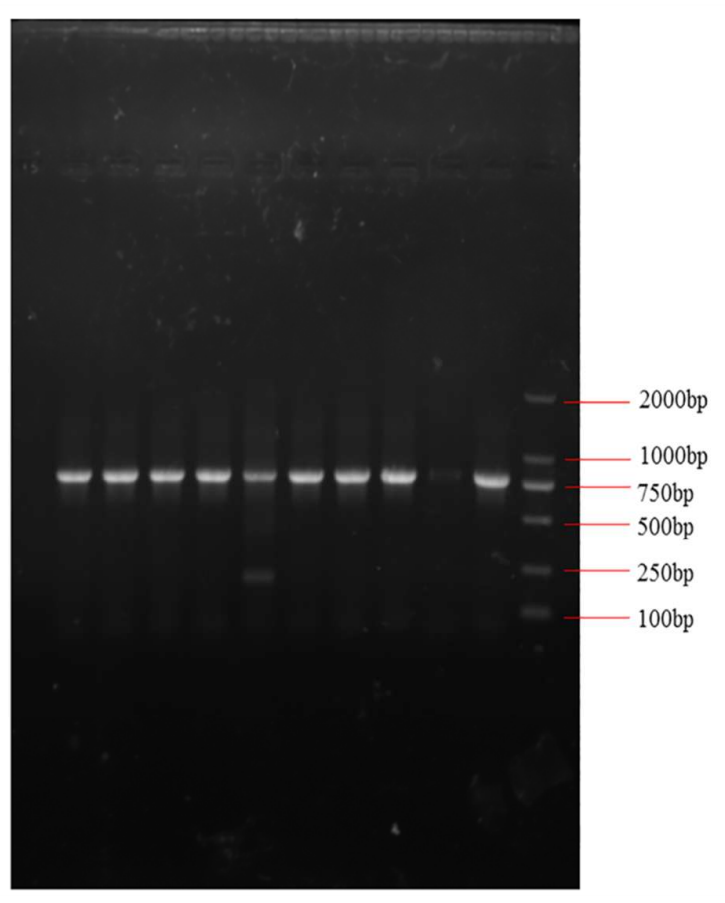




\title{
The amino acid sequences of the scFvs
}

\author{
1. The amino acid sequence of heavy chain
}

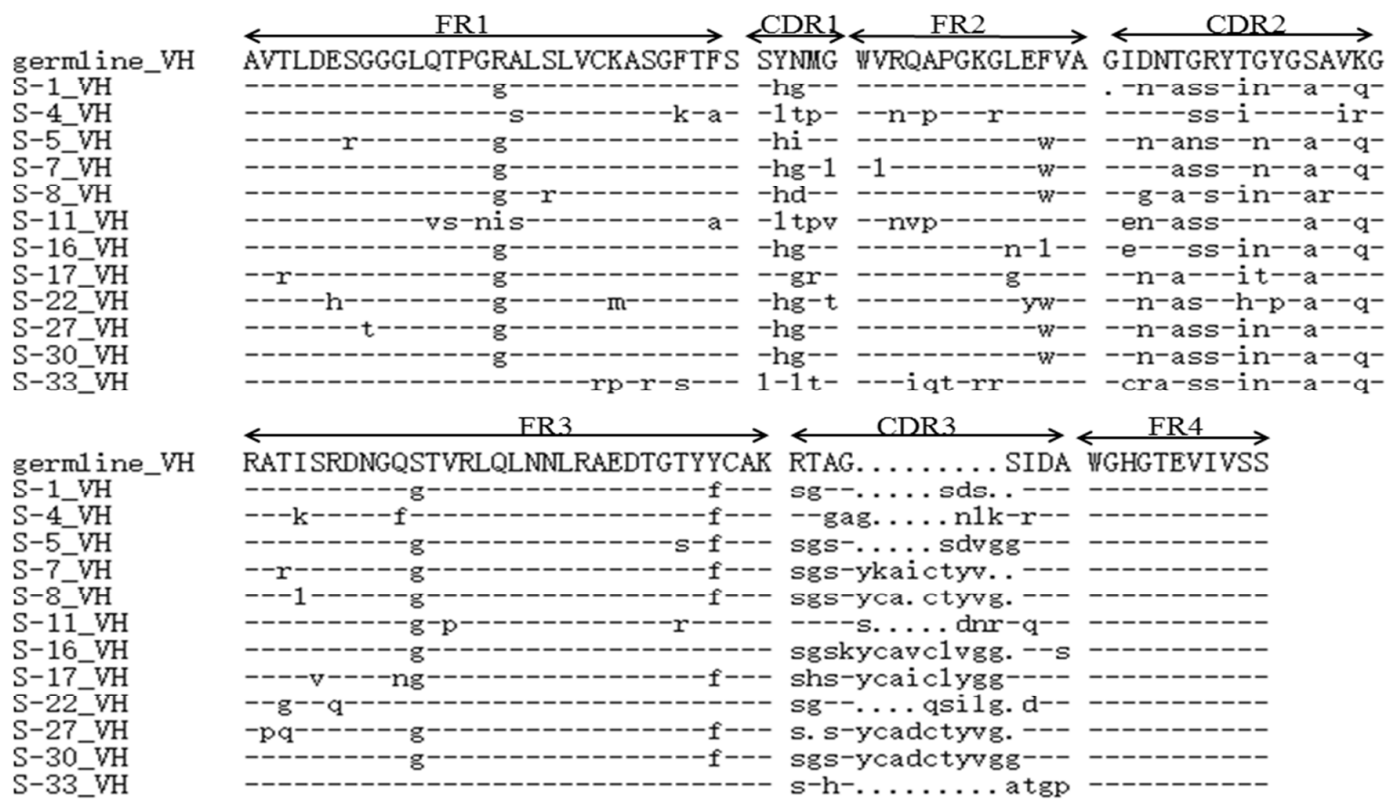

2. The amino acid sequence of light chain

\begin{tabular}{|c|c|c|c|c|}
\hline & FR1 & CDR1 & ER2 & $\leftarrow$ CDR2 \\
\hline mline_VL & ALTQPSSVSANPGGTVKITC & SGD. SSYYG & WYQQKAPGSAPVTVIY & DNTNRPS \\
\hline & $-------r-----e-i----$ & $--s 1-\mathrm{nn}--$ & $-----s-------1--$ & ngn---- \\
\hline & $-----a-------e-\bar{i}----$ & $--\operatorname{sipgn}--$ & $---p-s-------1--$ & aiv-t-- \\
\hline & $-----a-------e-\mathbf{i}----$ & $--\operatorname{sg}-\operatorname{nn}--$ & $-----s-------1-$ & ngn---- \\
\hline & $-----a--------------$ & $--s \cdot--n--$ & ---------------- & $f-n i-r-$ \\
\hline & 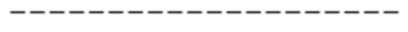 & $1--.-\mathrm{n}---$ & $-----\mathrm{q}-----\mathrm{e}-\mathrm{t}--$ & $-\operatorname{an}--x-$ \\
\hline & $-------e^{-------------~}$ & $--\operatorname{agpg}---$ & ---------------- & $m-s-g--$ \\
\hline & $-----\mathbf{a}---------\mathbf{i}----$ & -- s. $g-x--$ & ---------- & $\operatorname{tvn}-s--$ \\
\hline & $-----a--------------$ & $--s g-n---$ & $-----s-------1--$ & $\mathrm{n}-\mathrm{sv}---$ \\
\hline & $-----a-------e-i$ & $--s g-\operatorname{nn}--$ & $-c-1-s----------$ & ng ----- \\
\hline & $-----a-------e^{-i}----$ & $--s g-n n--$ & $-----s-------1--$ & ngn---- \\
\hline & $-------------\theta-i----$ & $--s g-\operatorname{mn}--$ & $-----s-------1--$ & i gn---- \\
\hline & $-----a-------e-i----$ & $--s g-n k 1 w$ & $-v-----w------1 w$ & $n--1 e^{--}$ \\
\hline & & & CDR3 & FR4 \\
\hline$-V L$ & NIPSRFSGSKSGSTATLTIT & VRADDNAVYYC & ASTDSSSTAGI & AGTTLTVL \\
\hline & $----t----g^{-}----$ & $-q-e-e--1$ & - ggikr-- & 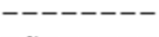 \\
\hline & $---------t----g----1$ & $-q^{---}-e^{---1}$ & - phasmppsg. - & $-q^{-------~}$ \\
\hline & $------\mathrm{t}----\mathrm{g}-0$ & $--q-e-e---f$ & - ggi-r-n. - - & $\begin{array}{ll}------- \\
----1\end{array}$ \\
\hline & ----------------- & $------b----$ & - pgiyr--ns. - & ------- \\
\hline & $-----e---t--$ & $-q^{-}-e^{-----}$ & $-v \operatorname{try}--i s t-$ & --- \\
\hline & $d--------------g$ & $-----e----1$ & - ghasm-pag. - & -------0 \\
\hline & -----ー---ー----gp-1 & $--e-e---f$ & - ggy-x--yg. - & \\
\hline & 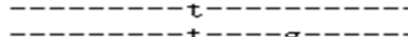 & & ggw-r--n. - - & \\
\hline & $\begin{array}{l}---------t-1 \\
--------1-1\end{array}$ & $q-e-e$ & $\mathrm{~g} g--\mathrm{r}--\mathrm{n} . \cdot-$ & \\
\hline & $\begin{array}{l}---------\mathrm{t}-- \\
---------\mathrm{t}--\end{array}$ & 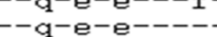 & $\begin{array}{l}\text { ggyrqeqy. . - } \\
\text { ggi-r-n. - }\end{array}$ & ------- \\
\hline & $\mathrm{f}-------\mathrm{r} 1--$ & & g. -rqeqg. . - & \\
\hline
\end{tabular}

